\title{
pensamento, experiência e o tempo do ócio na educação infantil
}

\author{
gabriela venturini ${ }^{1}$ \\ rede municipal de porto alegre; rede marista de educação, brasil \\ orcid id: https:/ / orcid.org/0000-0002-8181-3411 \\ betina schuler ${ }^{2}$ \\ universidade do vale do rio dos sinos/unisinos, brasil \\ orcid id: http:/ / orcid.org/0000-0002-2424-7601
}

Este artigo busca examinar como os conceitos de pensamento e de interesse são descritos nos três principais documentos que regem a Educação Infantil brasileira no presente - Lei de Diretrizes e Bases da Educação Nacional/1996, Diretrizes Curriculares Nacionais para a Educação Infantil/ 2010 e Base Nacional Comum Curricular/2018 da Educação Infantil - e suas implicações para as relações entre infância e pensamento. Para tanto, parte dos estudos da Filosofia da Diferença, de autores como Kohan, Larrosa, López e Ribeiro, entre outros, para problematizar o pensamento atrelado ao interesse individual no contemporâneo. Pode-se constatar o quanto o pensamento é operado como resolução de problemas nesses documentos, a partir de uma lógica neoliberal que vai se deslocando cada vez mais de um interesse coletivo para um interesse individualizante. Além disso, pode-se descrever todo um funcionamento de uma sociedade disciplinar deslocando-se para uma sociedade do desempenho, em que há um grande privilegiar das práticas de avaliação e registro da "produção" das crianças. A partir disso, no conceito de infância do pensamento e no conceito de experiência, buscamos a possibilidade de viver outras relações com as infâncias e as temporalidades na escola de Educação Infantil, tomando a potência do ócio e da brincadeira como brecha de respiro em meio a rotinas entupidas e, ao mesmo tempo, esvaziadas de sentido.

palavras-chave: educação infantil; infância; pensamento; interesse; ócio.

\section{thought, experience and free time in child education}

abstract

This paper aims to examine the way that the concepts of thought and interest have been described in the three main documents that currently guide Brazilian Child Education National Education Guidelines and Bases/1996, National Curriculum Guidelines for Child Education/2010, and National Curriculum Basis/2018 for Child Education - and their implications for relations between childhood and thinking. In order to do that, we have relied on studies in the philosophy of difference, considering authors such as Kohan, Larrosa, López and Ribeiro, among others, to problematize thought as linked to individual interest. We notice how much thought has been regarded as a problem-resolution tool in these documents, following a neoliberal logic that has been increasingly displaced from collective to individualized interest. Furthermore, the whole functioning of a disciplinary society is evident in the documents, as the latter moves towards a performance society, with greater emphasis on assessment practices and records of children's "production." We consider, both in the concept of childhood and the concept of experience, the possibility of experiencing other

\footnotetext{
${ }^{1}$ E-mail: venturinigabii@gmail.com

2 E-mail: betinaschuler@hotmail.com
} 
pensamento, experiência e o tempo do ócio na educação infantil

relationships with childhoods and temporalities in schools, and the power of both free time and play as open breathing spaces among routines that are both full of compulsory activities and empty of meaning.

keywords: child education; childhood; thought; interest; idleness.

\section{pensamiento, experiencia y el tiempo del ocio en la educación infantil}

resumen

Este articulo busca examinar de qué manera los conceptos de pensamiento y de interés son descriptos en los tres principales documentos que rigen la Educación Infantil brasileña en el presente - Ley de Directrices y Bases de la Educación Nacional/1996, Directrices Curriculares Nacionales para la Educación Infantil / 2010 y Base Nacional Común Curricular/2018 de la Educación Infantil- y sus implicaciones para las relaciones entre infancia y pensamiento. Con este objetivo, se parte de los estudios de la Filosofía de la Diferencia, de autores como Kohan, Larrosa, López y Ribeiro, entre otros, para problematizar el pensamiento vinculado al interés individual en lo contemporáneo. Se puede constatar la proporción en que el pensamiento es operado como resolución de problemas en estos documentos, a partir de una lógica neoliberal que se va trasladando cada vez más de un interés colectivo para un interés individualizante. Además de esto, se puede describir todo el funcionamiento de una sociedad disciplinar desplazándose para una sociedad de desempeño, en la que hay un gran privilegio de las prácticas de evaluación y registro de la "producción" de los niños. A partir de esto, en el concepto de infancia del pensamiento y en el concepto de experiencia, buscamos la posibilidad de vivir otras relaciones como las infancias y las temporalidades en la escuela de Educación Infantil, tomando la potencia del ocio y de los juegos como una brecha de respiro en medio de rutinas sobrecargadas y, al mismo tiempo, carentes de sentido.

palabras clave: educación infantil; infancia; pensamento; interés; ocio. 
pensamento, experiência e o tempo do ócio na educação infantil

\section{uma introdução}

Este artigo é fruto de uma pesquisa cujo intuito foi analisar como os conceitos de pensamento e de interesse se colocavam em alguns documentos que regem a Educação Infantil no Brasil hoje, a saber: Lei de Diretrizes e Bases da Educação Nacional (919496/1996) ${ }^{3}$, Diretrizes Curriculares para a Educação Infantil ${ }^{4}$ (2010) e Base Nacional Comum Curricular ${ }^{5}$ (2018). O objetivo deste texto é analisar, a partir da pesquisa norteadora, como os conceitos de pensamento, experiência e tempo, aqui defendido como tempo do ócio, são operados na Educação Infantil brasileira hoje.

De antemão, cabe ressaltar que nos documentos foram encontradas algumas fortes regularidades que compõem o lugar e a imagem de uma criança autora, capaz, protagonista, criativa, potente e autônoma, com interesses individuais, empreendedora de si mesma. Algumas práticas discursivas destacaram-se: os caráteres salvacionista e desenvolvimentista da escola, em adesão à lógica neoliberal, a fim de formar e preparar indivíduos para o mercado atual de trabalho; o aprender a aprender ou o empreendedorismo de si; o individualismo em detrimento do coletivo; os sintomas da transição de uma sociedade disciplinar para uma sociedade do desempenho; e a necessidade do controle, vista nas práticas de registro e avaliação. Percebeu-se que tais práticas discursivas funcionam em meio a complexas relações de poder e de saber, assim como afirmado por Foucault (1991). Também se destacam, amparados nisso, alguns discursos políticos educacionais que "operam no sentido de formar, posicionar, regular, normalizar, governar e, principalmente, tornar produtivos cada vez mais precocemente, os cidadãos" (Agostini, 2017, p. 140). Em linhas gerais, essa é também uma forte e importante regularidade encontrada na BNCC.

Faz-se necessário ressaltar que há também outros pontos que chamam a atenção como regularidades nesse documento. Um deles é o interesse aparecendo no sentido

\footnotetext{
${ }^{3} \mathrm{LDB}$.

${ }^{4}$ DCN.

5 BNCC.
} 
pensamento, experiência e o tempo do ócio na educação infantil

coletivo de relação com diferentes modos de vida e ampliação de repertório cultural, o que evidencia a importância desse aspecto, uma vez que consta em uma política pública educacional com força de lei nos tempos em que vivemos, mesmo que ainda exista um forte deslocamento para o interesse individual, para "atender adequadamente a seus interesses" (dos alunos). Essa regularidade é evidência da necessidade de a criança demonstrar interesse constantemente. $\mathrm{O}$ enunciado do interesse como algo natural das crianças vem com os estudos de Rousseau e Hebart, sendo hoje fortemente capturados por uma perspectiva neoliberal que transforma alunos em clientes.

A partir desses argumentos, pensamos que este seria um importante e maior deslocamento: o de um interesse coletivo para um interesse individual, presente em um discurso que não vincula a criança ao pensamento, mas ao desenvolvimento de habilidades e competências, as quais podem ser registradas em nome da transparência e da entrega ao cliente daquilo pelo qual ele anseia. Há o paradoxo do enunciado da criança protagonista, da criança e seus interesses como centro do processo educativo, juntamente do enunciado do registro e da visibilidade permanente na produção das crianças. Por isso, podemos problematizar se as crianças estão no centro dos processos educativos ou a avaliação e o registro de sua produção a qualquer custo.

Tais achados embasam a ideia, já reforçada e trazida por autores como Han (2015) e Sibilia (2016), de que a sociedade da linguagem instrumental, da utilidade pragmática, da aceleração, da fragmentação, do entupimento de informações, do cansaço e do desempenho em que vivemos hoje faz coincidir a liberdade individual e a coerção dos outros e de nós mesmos sobre a gente. Partimos aqui de um posicionamento teórico-metodológico para analisar práticas discursivas, com base em Foucault, uma vez que entendemos que aquilo que trazemos como "achados" neste artigo faz parte do que produzimos e do que nos produz como professoras, educadoras e defensoras da luta na Educação Infantil brasileira.

Na lógica apontada, o exercício do pensamento cede espaço ao atendimento dos interesses individuais e ao seu registro, objetivando alcançar específicas habilidades e 
competências focadas em reconhecer e resolver problemas, as quais podem ser esquadrinhadas. Outras ressalvas que trazemos são a liberdade de ensinar e aprender e a importância da conversação com a tradição, com diferentes culturas e com diferentes modos de vida. Sob a ótica deste artigo, essas ressalvas são vistas como brechas que podem tornar-se potência para potencializar o pensamento. Por fim, destacamos que nosso intuito é também diferenciar o conceito de experiência que aparece na BNCC com o conceito de experiência operado pela Filosofia da Diferença, sendo essa última atravessada pelo ócio e pelo exercício do pensamento. Este exercício se dá com o objetivo de propor outro olhar para esses conceitos, não se bastando na ideia de comparar ou avaliar. Pensar junto e pensar com o outro amparam o que nos propomos a fazer nesta escrita, pois, antes de tudo, defendemos que é preciso a experiência do pensamento e o tempo do ócio neste e em qualquer outro espaço de educação.

das regularidades e dos deslocamentos enunciativos nos documentos analisados: o interesse individual e o registro na educação infantil

Lendo a LDB/96, as DCNEIs/10 e a BNCC/18, as discussões encontradas provocam muitas inquietações, e pensamos ser esse, justamente, o papel de uma investigação. Contudo, antes de vincular, entre si, os conceitos com os quais nos comprometemos, julgamos ser importante explicar alguns caminhos seguidos nesta escrita, bem como reiterar e mostrar, com maior nitidez, as regularidades e os deslocamentos que interpretamos ao examinarmos os documentos.

Como já afirmado, a BNCC/18 traz o lugar e a imagem de uma criança autora, capaz, protagonista, criativa, potente e autônoma, com interesses individuais, empreendedora de si mesma. Junto a isso, também estão presentes algumas práticas discursivas, como as de caráter salvacionista e desenvolvimentista da escola, que aderem à lógica neoliberal a fim de formar e preparar indivíduos para o mercado atual de trabalho; o aprender a aprender ou o empreendedorismo de si; o individualismo em detrimento do coletivo; os sintomas da transição de uma sociedade disciplinar para 
pensamento, experiência e o tempo do ócio na educação infantil

uma sociedade do desempenho (Han, 2015); e a necessidade do controle mediante práticas de registro e avaliação (Horn, 2017).

Trazemos para esta discussão o conceito de pensamento, amparadas na perspectiva da Filosofia da Diferença, a partir de autores, tais como: Foucault, Kohan, López, Larrosa e Sibilia, entre outros. Nesse sentido, o pensamento é visto como uma ação transgressora, um ato que promove a ruptura de dogmas e de preconceitos. O que defendemos é a ideia de que exercitar o pensamento poderia ser uma força da escola de Educação Infantil, assim como propor espaços e tempos de viver a experiência do ócio e do pensamento dentro desse espaço coletivo com o outro e por meio do outro.

Dando prosseguimento ao proposto e utilizando-nos da ordem cronológica dos documentos trazidos, explicitamos que, inicialmente, operamos com alguns trechos de cada um. Explicamos que, de modo geral, "a LDB foi a legislação que complementou e efetivou os princípios constitucionais relativos ao direito social à educação, estabelecendo que a Educação Infantil, que inclui o atendimento em creches e préescolas, é a primeira etapa da Educação Básica" (Agostini, 2017, p. 43). Essa lei foi o documento que legitimou, para as crianças, o que sempre foi de direito, mas nunca antes legitimado: a educação escolarizada. Dentre os princípios gerais, encontramos: “II- liberdade de aprender, ensinar, pesquisar e divulgar a cultura, o pensamento, a arte e o saber" (Brasil, 1996, s/p). Isso aparece e tem continuidade nos demais documentos, mas talvez não de maneira tão enfática, pois as Diretrizes falam de "liberdade de expressão nas diferentes manifestações artísticas e culturais" (Brasil, 2010, p. 16), e a BNCC/18 diz que as crianças são “orientadas para a emancipação e a liberdade, e não para a submissão" (Brasil, 2018, p. 39).

Nas Diretrizes, como já mencionado, encontramos certo início de mudança de vocabulário e de perspectiva, pois se fala de uma criança que produz cultura; com isso, acontece um deslocamento do interesse, que, na LDB/96, era social e que agora se torna individual - o interesse individual da criança. Entretanto, ainda parece haver certo posicionamento com a tradição, pois existe o outro, o respeito ao outro e às diferentes culturas. Isso é retratado na página 20 da seguinte forma: “a apropriação, pelas 
crianças, das contribuições histórico-culturais dos povos indígenas, afrodescendentes, asiáticos, europeus e de outros países da América" (BRASIL, 2010, p. 20); ou então, na página 24: "flexibilizar, se necessário, calendário, rotinas e atividades, respeitando as diferenças quanto à atividade econômica dessas populações" (Ibidem, p. 24).

Contudo, o que fica de enunciado regular mais forte nesse documento, além do deslocamento do interesse, é a prática desenfreada do controle e da avaliação, pautada na lógica do desempenho, conforme apontado por Horn (2017), já naturalizado pelos educadores nas atividades mais cotidianas. Essas práticas mostram-se como o outro do pensamento: "viver diferencialmente o cotidiano escolar demanda habitar este desassossego da linguagem, assumindo o trabalho do pensamento como gesto de divergência afirmativa em busca de criação, recusando a reflexividade dócil rumo à compreensão" (Ribeiro, 2011, p. 626). Ou seja, afirmar que o pensamento é o outro do interesse ancora-se em desnaturalizar as práticas discursivas e em ampliar o olhar para além das naturalizações, no presente, que ditam como discurso de verdade a força do registro exacerbado como uma nova tecnologia de moralização na Educação Infantil quando pensamos na sociedade de desempenho, na qual estamos todos imersos (Han, 2015).

Em se tratando da $\mathrm{BNCC} / 18$, há também pontos que chamam a atenção enquanto regularidades: o interesse aparece no sentido coletivo com a lidação com diferentes modos de vida e ampliação de repertório cultural. Ressaltamos, assim e mais uma vez, a importância desse aspecto por atualmente constar em uma política pública educacional com força de lei. Todavia, como também já dito, percebe-se o deslocamento para o interesse individual, para "atender adequadamente a seus interesses".

Amparadas em Horn (2017, p. 50), salientamos que, ao olhar para a BNCC/18, foi possível entender que "o tipo de análise que praticamos não trata do problema do sujeito falante, mas examina as diferentes maneiras pelas quais o discurso desempenha um papel no interior de um sistema estratégico em que o poder está implicado, e para o qual o poder funciona” (Foucault, 2006, p. 253). Por isso, “[...] o poder não é nem fonte 
pensamento, experiência e o tempo do ócio na educação infantil

nem origem do discurso. O poder é alguma coisa que opera através do discurso, já que o próprio discurso é um elemento em um dispositivo estratégico de relações de poder" (Ibidem, p. 253).

Problematizamos, então, o funcionamento contemporâneo das relações de poder que invadem a Educação Infantil, no Brasil, que pede que as crianças se coloquem e sejam colocadas a todo instante em discurso: narrando seus interesses, registrando suas mínimas "produções", comprovando seu desenvolvimento e progresso. A criança é abordada como protagonista; a criança está no centro do processo educativo; a criança somente aprende a partir de seus interesses individuais. Escrutina-se o corpo infantil, dissecam-se seus funcionamentos, esquadrinham-se seus menores movimentos, e entrega-se esse registro às famílias como prova do bom rendimento das escolas e dos alunos.

$\mathrm{O}$ interesse rastreado na $\mathrm{BNCC} / 18$ mostrou-se fortemente vinculado ao utilitarismo, e amparamo-nos em Han (2015) para explicá-lo. Os enunciados regulares do interesse, no documento, são marcados por termos como: reconhecer, resolver, usar, comunicar, falar, entre outros. Coloca-se o sujeito na produção de si mesmo, funcionando por e para recognição e pró-atividade, produzindo-se, pois, desde a Educação Infantil, com a subjetivação do resolvedor de problemas, do falador de si e do cliente atendido em seus desejos individuais.

Uma última regularidade apresentada na Base, nesta análise, é o enunciado do desenvolvimento, ponto este que aparece desde a LDB/96, sutilmente, e mais claramente nas Diretrizes, com muita força neste último documento. Cabe reafirmar que o pensamento é o outro do desenvolvimento, porque, para pensar, não é preciso desenvolver o pensamento, mas fazer. Para Ribeiro (2011), isso pressupõe apenas uma lidação que ultrapassa o conhecimento como meramente reflexivo e desenvolvimentista.

Um deslocamento também importante a ser destacado é o pensamento como reflexão e recognição, o qual se faz presente em todo o percurso analítico. Porém, toma outras formas a partir do léxico empresarial que descreve competências e habilidades 
para os sujeitos, cada vez mais refinadas e detalhadas, necessitando de registro permanente, conforme aparece mais fortemente na BNCC/18.

Ainda outro deslocamento acontece em relação à individualização dos sujeitos, a qual também se refina nos documentos, mostrando-se muito mais na Base, mas já aparente nas Diretrizes e na LDB/96. Essa prática discursiva do individual dá força para as práticas avaliativas e de registro, sintomas do desempenho, como bem descrito por Han (2015). É a produção de sujeitos por meio de competências para que possam atender aos seus interesses e gerir a si próprios.

Reiteramos o quanto de ausência do enunciado do pensamento foi constatado nos documentos examinados. Além de praticamente não aparecer, quando isso aconteceu, ele sempre esteve atrelado a outro aspecto ou habilidade, ou seja, o pensamento cola-se a algum desenvolvimento, nos documentos, e às habilidades e competências.

A partir de tudo isso, quando resumimos os achados neste deslocamento maior do interesse coletivo para um interesse individual, sustentado pela lógica neoliberal das habilidades e competências, que esvazia e dificulta possibilidades de pensamento da criança a partir das práticas sugeridas nos documentos, poderíamos perguntar às crianças, por exemplo, se gostariam que suas professoras as gravassem, fotografassem e fizessem planilhas ou se prefeririam que as professoras interagissem e brincassem com elas. O que receberíamos como resposta? Essa sociedade do desempenho que faz coincidir liberdade individual e coerção, vai cedendo cada vez mais espaço ao atendimento dos interesses individuais, do seu registro, objetivando alcançar específicas habilidades e competências, focadas em reconhecer e resolver problemas.

Por esses motivos, "são as próprias verdades educacionais talhadas pelo conhecimento pedagógico historicamente lastreado que demandam outra experiência do pensar" (Ribeiro, 2011, p. 626). Desse modo, construímos o argumento de que, inspiradas por tais regularidades e deslocamentos descritos a partir do exame dos materiais, é possível tensionar outras coisas em se tratando da relação entre pensamento, infância e crianças, o que exigiria outra relação com o tempo, visando ao 
pensamento, experiência e o tempo do ócio na educação infantil

fortalecimento do ócio e vinculando a este o ato de brincar. Assim, “[...] faz-se necessário suspeitar do gesto virtuoso que, ao naturalizar a clássica relação entre conhecimento e educação, finda por retroalimentar e fortalecer a maquinaria da linguagem, sequestrando do viver as possibilidades da experiência do pensamento" (Ribeiro, 2011, p.627).

Utilizando-nos desses pontos de análise e de tais argumentos, operamos, agora, neste espaço de arquitetura escrita, com alguns conceitos que, como falado anteriormente, julgamos importantes para a Educação Infantil enquanto espaço de formação e de potência para com a vida em tempos de interesse: o pensamento, o tempo e o ócio vinculados ao conceito da experiência. $\mathrm{O}$ intuito é pensar a experiência que a BNCC (2018) tanto enfoca e a experiência do pensamento a partir da Filosofia da Diferença como outra possibilidade de tomarmos essa questão.

\section{pensamento, infância e experiência}

Em se tratando do pensamento, podemos marcar que "pensar é mexer num dicionário, dar potência a algumas palavras; calar outras, travar, afinal, uma luta de sentidos e significados" (Kohan, 2007, p. 48). Pensar, pois, tem a ver com selecionar, colecionar, conversar, escutar, falar, desenhar.

O que acreditamos ser urgente para problematizar é que pensar não se trata de chegar a algum lugar, seja ele qual for. Nem sempre e nem em todo momento é necessário pensar para resolver problemas, para "evoluir", para desenvolver-se, para atender aos seus interesses, para ter prazer, para preparar-se para o futuro, para atingir determinadas habilidades e competências, para ser registrado e medido. Não é preciso pensar para algo enquanto resultado. Preferimos tomar o pensar para dar potência a ele mesmo, para retroalimentar a vida e o mundo, para o próprio pensamento, para questionar a naturalização das coisas, para estar de outros modos consigo e com os demais.

Isso porque "pensamos porque algo acontece conosco, a partir das coisas que acontecem conosco, a partir do que vivemos, como consequência da nossa relação com 
o mundo que nos cerca" (Barthes, 2005, p. 57 apud Larrosa, 2018, p. 22). Pensamos porque algo externo nos toma, porque é a vida que implica o pensamento. Arendt (2000) explica que a condição do pensamento é o humano, é a experiência que imprime em nós a "necessidade de repensar, de retornar às ideias que tínhamos sobre as coisas, porque o que a experiência nos mostra é exatamente a insuficiência ou a insatisfação do nosso pensamento anterior [...]. O que faz com que a experiência seja assim é isto: que temos de tornar a pensar" (Arendt, 2000, p. 22). Um pensamento nunca será igual, nem poderá ser pensado na mesma medida - sempre será outro, mesmo que seja sobre a mesma coisa.

Agora, entendemos que, para falar de certa condição de pensamento, há também uma condição que é a infância do pensamento. Não dizemos que somente a criança leva a pensar, mas o quanto a infância, tomada como condição da existência, e não como estágio cronológico, está vinculada ao pensar; o quanto essa ideia brincante de um pensamento crianceiro favorece o pensar sem ter que "dar contas", sem que ele precise evoluir, porque não seria da ordem da progressão linear. Infância como um olhar atento e aberto ao mundo, ao abismo, à comoção.

O conceito de infância do pensamento trabalhado por Kohan (2009) e por Bedin da Costa et al. (2017) é importante para se pensar a infância, cuja definição seria algo fora do tempo cronológico, fora daquilo que é estático e que se pode narrar de modo linear. Para Kohan (2009, p. 217), a “infância do pensamento" trata dessa "[...] infinita potência de recomeço no pensamento que a pergunta instaura e mostra que, em última instância, quando pensamos, estamos sempre no começo". É como se pensar não pudesse ser um final ou um produto, mas um pensamento infante, um novo começo. Ainda fazendo uso da afirmativa do autor:

Para dizê-lo com outras palavras: pensar de verdade, pensar-se a si mesmo, fazer da filosofia um exercício de se colocar a si mesmo em questão exige, a cada momento, ir até a mais recôndita infância do pensamento, começar a pensar tudo de novo como se nunca tivéssemos pensado, como se, a cada vez, estivéssemos pensando pela primeira vez. Assim, a infância é quase uma condição da filosofia. (Kohan, 2015, p. 217).

Pensar torna móvel todo discurso instaurado sobre aquilo que temos em relação 
pensamento, experiência e o tempo do ócio na educação infantil

às crianças, às infâncias, ao pensamento. Tornar possível uma infância do pensamento, um pensamento infante, brincante, criador, parece-nos abrir possibilidades para pensar outras coisas também na Educação Infantil. Pensar sob uma perspectiva filosófica, como fala Kohan (2007), significa também entrar em um universo mais próximo das crianças, ser e estar com elas em um sentido de igualdade - não de igualdade em termos de iguais, mas igualdade no sentido de um lugar juntos, o pensamento. Contudo, já dizia López (2008) que pensar junto não significa pensar o mesmo, como também não significa pensar certo ou errado (Kohan, 2015).

Pensamos que, por mais difícil que seja, em meio a tudo que hoje se vive dentro das escolas, um pensar crianceiro se faz necessário na relação que se estabelece entre crianças, entre adultos, entre adultos e crianças, para que haja tempo, espaço e ócio para o pensamento. Afinal, utilizando a afirmativa de Agamben (2017, p. 15): "devemos parar de fingir que sabemos o que é uma criança. A cultura, ou seja, a educação funda-se sobre essa ficção. Tudo o que sabemos da criança é que ela torna inútil tudo aquilo que acreditamos saber sobre o homem".

López diz que "só pensamos quando somos provocados de fora de nosso poder, de nosso saber, de nossa identidade pessoal" (2008, p. 55). Outra ressalva fundamental é a desnaturalização da condição de verdade que uma ideia necessita ter, principalmente dentro das escolas. Todos procuram, desde Platão até os dias de hoje, a verdade, o correto, o inquestionável, aquilo que, por assim ser, é válido, a partir de uma lógica da verdade original. Falar de algo dentro da escola precisa ser da ordem do saber, contrário àquele ou àquilo que não se sabe, como se ambos não pudessem se tratar de uma mesma ordem. Kohan (2015) defende a infância do pensamento e investiga a ideia da ignorância, a ignorância do não saber tudo e do não saber como todos.

Talvez, se essa potência da ignorância apontada por Kohan, este não saber, estivesse mais presente nas escolas de Educação Infantil e no campo da educação como um todo, menor seria a distância delas para com uma experiência formativa. Quando os documentos retratam um ideário de pensamento reduzido às habilidades e 
competências, não seria isso um esvaziamento daquilo que se mostra como cheio, como afirma Kohan? Um entupimento que não permite mais pensar? Como poderia o pensamento ser operado em uma experiência formativa nas escolas de Educação Infantil, tão entupidas de rotinas, de interesses, de registros, de verdades sobre o que as crianças são ou como deveriam ser?

A partir disso, entendemos que um conceito importante para tomar a infância do pensamento é o conceito de experiência, esse algo que nos acontece, nos atinge, se apodera de nós, nos transforma. Para falarmos da experiência, descrevemos e utilizamos aquela vinculada à Filosofia e à infância do pensamento e aquela operada pela Pedagogia da Infância, utilizada pelos Campos de Experiências da BNCC/18. Experiências com bases teóricas diferentes, mas que, em suas singularidades, auxiliam a pensar sobre o conceito.

Essa afirmativa traduz um argumento que carece operar sobre a experiência: o de que talvez a experiência sobre a qual o campo da Educação discursa seja uma invenção, uma vez que ela é tida como uma verdade. Assim sendo, talvez ela faça outras coisas daquilo que a BNCC/18 conota que ela faça. Como Kohan (2017, s/p) afirma na apresentação de sua coleção de livros Experiência e Sentido, é "a experiência, e não a verdade, é o que dá sentido à escritura". Em todos os livros dessa coleção, Kohan, junto com os demais autores, aborda elementos importantes para se pensar a experiência como o outro do interesse, como algo não determinado que não pode ser avaliado por seu desenvolvimento - como único e ao mesmo tempo comum e vinculado ao pensamento.

Trazendo a experiência como não determinada, problematizamos aquilo que encontramos no material empírico sobre experiência. Na LDB/96, encontramos quatro vezes a palavra experiência; nas DCNEIs/10, seis vezes; e, na BNCC/18, a palavra experiência aparece 26 vezes no texto - sem contar as vezes em que ela aparece repetidamente nos títulos Campos de Experiências. Perguntamo-nos: o que isso nos diz? Entendemos que diz sobre sua importância, pois está claramente e gradativamente em evidência. 
pensamento, experiência e o tempo do ócio na educação infantil

Não intencionamos quantificar isso, pois o objetivo é fazer um apanhado geral sobre a maneira como a experiência é colocada nos documentos e, a partir disso, sobre o que se propõe e o que ajuda a pensar sobre a relação entre pensamento e infância. Percebemos que o conceito vincula, nos três documentos, experiência a uma vivência/aprendizagem, preferencialmente que tenha "sentido". Nos documentos, experiência é aquilo que a criança vive e, por consequência, aprende; é o que ela guarda na memória, por isso o argumento de senso comum na educação de que as "experiências precisam ser significativas", quase como que um sinônimo de experimento.

Outro ponto corrobora a experiência que aqui está sendo discutida: os Campos de Experiências da BNCC/18. Segundo o MEC, na própria Base, os Campos de Experiências são descritos da seguinte forma: “[...] constituem um arranjo curricular que acolhe as situações e as experiências concretas da vida cotidiana das crianças e seus saberes, entrelaçando-os aos conhecimentos que fazem parte do patrimônio cultural" (Brasil, 2018, p. 38). São subdivisões, por áreas, daquilo que as crianças precisam viver para aprender. Aqui, ressaltamos um discurso presente no dia a dia das escolas: por ser uma experiência que parte do interesse da criança, esta é a protagonista; assim sendo, a experiência é sempre individualizada.

O que queremos dizer com isso é que o conceito de experiência que há na BNCC/18 parece estar colado à lógica de um experimento, de uma testagem, de um processo que leva ao descobrimento da aprendizagem, de uma parte do desenvolvimento da criança. Já o conceito de experiência que aqui tratamos a partir da Filosofia da Diferença pauta-se na questão da transformação, mas não no sentido de aprender para desenvolver e habilitar para.

Essa experiência de que falam Larrosa (1998) e Kohan (2003) é uma experiência que, quando coletiva, "os que a atravessam saem transformados, tanto quanto as relações entre eles e as de cada um consigo mesmo" (Ibidem, p. 14). Nessa transformação, não se deixa de ser outro; transforma-se a partir daquilo que se oferece e que se recebe; transforma-se na força que tem por ser também coletivo e comum. 
Kohan (2003, p. 15) ainda afirma que "o que se transforma é múltiplo: o que pensamos, a relação que temos com o que pensamos, o que sabemos, a relação que temos com o que sabemos, o que somos, a relação que temos com o que somos". Por isso, a experiência teria a ver com algo que nos acontece, e não com um experimento com roteiro e metas a serem alcançadas.

Neste momento, trazemos para discussão uma ideia que se encontra na pesquisa citada no início deste texto, a qual originou o artigo: a de que não é porque a experiência não pode ser dada que ela não pode ser planejada (e aqui o planejamento entendido justamente como a criação do professor que provocará encontros com as crianças, encontros entre pessoas, brincadeiras, imagens, palavras, sons, cores, texturas, etc.). $\mathrm{O}$ exemplo aponta para uma conversação entre essas duas afirmações sobre experiência: “é claro que a vivência como experiência não diz respeito a qualquer vivência, ou qualquer forma de vida, bem como nenhuma vivência pode ser uma repetição da vivência do outro, pois cada uma é singular". (Silva, 2018, p. 44). Assim, poderíamos pensar na potência do conceito de experiência quando associado ao pensamento e à infância na Educação Infantil em tempos de hegemonia do discurso do interesse.

Nesta construção, conseguimos expressar muito daquilo que acreditamos sobre do que pode se tratar a experiência: algo singular que, na escola, no exercício do pensamento, poderia estar em consonância com o bem comum, e não com o interesse individualizante. A experiência que, no início, propusemos contrapor àquela destacada pelos documentos é difícil de descrever. Aquela que tem a ver com uma sutilidade do espanto, sobre a qual escreveu Arendt (2000). A experiência é o encontro com os signos (López, 2008) e ela tem, sim - e muito! -, significado, mas não tem necessariamente a ver com o significado do interesse. Talvez tenha mais relação com o sentido do que com o significado. E, a partir disso, poderíamos perguntar: podemos restringir como importante para a criança somente o que parte do "seu interesse"? De onde vem o seu interesse? É natural da criança? As crianças podem interessar-se por aquilo a que não foram apresentadas?

Nós, professores e professoras, somos responsáveis por apresentar o mundo, ou 
pensamento, experiência e o tempo do ócio na educação infantil

melhor, os mundos às crianças. Mostrar o mundo e as coisas dele para as crianças é dar-lhes a possibilidade de se fazerem encantar, de chamar para a responsabilidade que significa estar na escola e habitar um espaço comum, de chamar a atenção das crianças para algumas coisas, de fazê-las escutar os outros e a si mesmas de algumas formas, de olhar para o mundo de algumas maneiras. Como a criança se interessará pelo que não conhece? Portanto, o mundo não precisa ser apresentado a ela?

Por isso, o pensamento estaria mais associado à experiência e à formação como uma possibilidade do que como uma lista de objetivos, habilidades, competências ou áreas disciplinares do conhecimento. Contudo, para pensar, precisamos de materialidade: precisamos de cores, de texturas, de sons, de palavras, de músicas, de imagens, de pessoas, de livros, de conceitos, de espaços, de poesia, de textos, de temporalidades, de ócio.

Como já afirmado aqui, é importante destacar, mais uma vez, o quanto a experiência percebida na $\mathrm{BNCC} / 18$ está relacionada a determinadas verdades. Experiência que diz respeito a propor às crianças que vivam explorações, sensações, desafios, entre outros, para que tenham muito significado. Experiências que se tornarão aprendizagens sólidas e significativas também, por sua vez.

Todavia, podemos entender que uma experiência que se opera com o pensamento é algo cujo "essencial não se encontra na série de constatações de uma verdade histórica" (Kohan, 2003, p. 16). Kohan (2003) ensina que verdade e experiência habitam lugares diferentes e de complexidades não semelhantes. Sendo assim, a experiência de que tratamos aqui é, ela mesma, uma experiência que promove a vida sem necessidade de estar linearmente posta, porque isso não garantiria o sentido e o valor do que se experencia.

Desse modo, "experiências nas quais as crianças podem construir e apropriar-se de conhecimentos por meio de suas ações e interações com seus pares e com os adultos, o que possibilita aprendizagens, desenvolvimento e socialização" (Brasil, 2018, p. 35) parece operar com algo muito mais como experimento e vivência. Entretanto, podemos operar com a experiência não como verdadeira ou falsa, mas "uma experiência é 
sempre uma ficção; é algo que não se fabrica a si mesma, que não existe antes e que encontrará o existir depois" (Kohan, 2003, p. 16). Tal compreensão faz com que a relação da experiência desacomode aquilo que é verdade e afirme uma potência de exercício de pensamento e de vida, mas que passará sempre por certa conversação com a tradição, conforme posto na BNCC.

Quando pensamos nesse aspecto, temos de ter um cuidado: o encantamento não pode ser confundido com transformar a escola em mundo Disney, muito menos com tornar esse espaço um circo, entoando o discurso da felicidade a todo momento (Seibert, 2019). Não é disso que se trata, até porque o exercício de pensamento que se coloca para pensar a vida a toma em suas mais variadas dimensões, incluindo a perda, o sofrimento e tantas outras coisas difíceis que atravessam nossas vidas e também a vida das crianças que não vivem em um conto de fadas social, como, por exemplo, as infâncias atravessadas no presente pela pandemia do novo corona vírus.

É preciso problematizar os currículos entupidos de registros e a potência do ócio também na Educação Infantil. Vinculamos aqui o ócio não ao não fazer nada, mas ao não fazer algo que tenha que produzir algo útil pragmaticamente. Daí a potência do ócio quando se pensa no exercício de pensamento em escolas de Educação Infantil como esse espaço e tempo para o pensamento, para a lidação com a vida, consigo, com os demais, com o que nos atravessa no presente que nos cabe. Sabe-se que o brincar é uma das maneiras mais potentes que a criança utiliza para estar no mundo, para comunicar-se com ele e, muitas vezes, para sobreviver nele. E como relacionar o pensamento da infância com um ócio brincante?

\section{o pensamento e o ócio na educação infantil: o brincar}

Defendemos aqui que o ócio, para a criança, está fortemente marcado na brincadeira (não no brinquedo como consumo), uma vez que, para a Filosofia da Diferença, o brincar pode significar o tempo do não fazer, e não o não fazer nada, mas o não fazer para ter o que fazer. Tal ideia desloca-se da produção e do resultado. O que afirmamos é que a brincadeira se basta só para a criança, pois dá tempo para o 
pensamento, experiência e o tempo do ócio na educação infantil

pensamento, produz pensamento e se constituiu por meio do ócio.

Não se trata de uma defesa do fazer nada. Também não é uma defesa do valetudo na Educação Infantil. É uma defesa das brechas para um modo mais interrogativo de estar nas escolas. E é também um modo de compreender a Educação Infantil e as crianças sem medições, avaliações, julgamentos e esquadrinhamentos de tantas ordens que vivemos no presente.

Assim, afirmamos que brincar é para a criança a forma mais importante de conexão com o mundo e consigo, é algo que ela faz sem que ninguém ensine ou mostre como fazer, assim como traz Pulino (2003). A brincadeira acontece com aquilo que a criança tiver à sua disposição; emerge e acontece, por esse motivo, o brincar não é ensaiado, e, muito possivelmente, aquilo que as crianças sentem nesses momentos não será vivido de novo, não será repetido. São esses momentos de ócio, de brincar, que vão atribuindo os sentidos individuais e coletivos das crianças; são esses momentos, por vezes micro, que proporcionam que a criança se constitua e constitua seus modos de existência.

Para Pulino, a brincadeira "tira o mundo do lugar e cria um não lugar" (2003, p. 221). Ao trazer tal fala, acreditamos que, para o pensamento, é preciso tempo, e o ócio significa esse tempo - tempo para criar, para brincar e para existir em um "não lugar" que possa suspender o mundo que pisoteia a criança a partir das tantas práticas discursivas utilitaristas. Um tempo para que ela possa experimentar a vida e o pensamento de outros modos. Quando trazemos a brincadeira como o tempo do ócio, o que queremos defender é essa suspensão que a brincadeira, por seu caráter de ficcionar a vida, permite. Contudo, ficção não como o outro do real, e sim como possibilidade de pensamento.

As crianças brincam sempre e brincam com aquilo que possuem, mesmo que seja com elas mesmas, com seu corpo, suas mãos, com o mundo que as cercas, com aquilo que elas têm. Dito isso, como poderíamos vincular o pensamento, o ócio e o brincar como uma experiência formativa? Uma experiência criativa-formativa?

Para tentar descrever a ideia dessa experiência formativa, trazemos o conceito 
da "temporalidade" (Carvalho, 2015) como constituinte do tempo do ócio ao qual nos referimos. Apesar de Carvalho (2015) não fazer relação das temporalidades da escola de Educação Infantil exatamente com o ócio, o autor afirma que a temporalidade é a relação das crianças no e com o tempo.

Ousamos problematizar que, talvez, essa relação seja potencializadora do pensamento e que ela pode acontecer por meio do ócio permeado pelo brincar. Ou seja, a temporalidade traduz a relação que fazemos da brincadeira como ócio e como possibilitadora de exercícios de pensamento. Ao utilizar tal conceito, o autor ainda explica que a relação que a criança tem com o tempo é "o tempo do prazer, da fruição e da descoberta" (Carvalho, 2015, p. 128-129). Nesta escrita, a descoberta e a fruição são aportes para os exercícios de pensamento que acontecem em meio ao ócio.

As brincadeiras infantis estão relacionadas a um universo das crianças e construído por elas. As crianças organizam e criam suas brincadeiras a partir das próprias ideias e regras; muitas vezes, inclusive, retirando outras crianças desses momentos, tamanha importância que eles têm para elas. É como se a vida delas dependesse disso. Marcamos a importância de que, para que o brincar seja intenso, é necessário que a criança esteja totalmente imersa neste "não lugar", afirmado por Pulino (2003). Porque é este "não lugar", ainda não territorializado, que traz a possibilidade de a criança, por meio do ócio da brincadeira, potencializar esse espaço como o seu lugar, ocupando subjetivamente um lugar dentro desse não lugar. As crianças criam mundos brincando, e, ao nosso ver, as escolas de Educação Infantil podem ser a potência de estarem atentas ao brincar, vendo-o como modos de estar com os demais, no mundo e com o pensamento.

Dessa maneira, podemos entender que as crianças criam mundos, criam escapes, criam possibilidades, criam pensamentos ilimitados. E eis que muitos nos perguntam: mas criança pensa? Engelman (2009, p. 34-35) responde que “brincar é fazer da razão uma razão inconstante. Brincar é descanalizar os devires em prol da criação [...]. Aquele que brinca desloca a repressão social, os padrões de conduta engessados [...]". Porém, para isso, precisamos de escolas que deem tempo: tempo para brincar, tempo para 
pensamento, experiência e o tempo do ócio na educação infantil

falar, tempo para escutar, tempo para se mexer, tempo para estar consigo e com os demais, tempo para o silêncio, tempo para a pergunta, tempo.

Problematizando o tempo do ócio como o tempo da brincadeira, retomamos os estudos de Carvalho (2015) sobre a temporalidade, uma vez que não podemos imaginar esse brincar mapeado pelo ócio sem estar imerso nas temporalidades infantis. Entretanto, o que evidenciamos dentro dessa argumentação sobre o brincar, pautada na análise dos documentos que fizemos, é que, além de não serem respeitados, os tempos têm sido fortemente atacados pelos interesses neoliberais, que afirmam que tempo é dinheiro e que tempo não pode ser perdido, isso tudo desde muito cedo. Muitas vezes, o tempo da brincadeira nas escolas é percebido dessa forma e atropelado por aquilo que desenvolve, habilita, aprimora. Carvalho (2015) afirma também que tais tempos não são, geralmente, respeitados nas instituições de Educação Infantil. O autor diz que "as crianças não têm muitas opções de escolha, pois as propostas previstas na rotina, devido ao modo como ritualizam o tempo, não possibilitam que meninos e meninas expressem suas ideias, intenções e pontos de vista" (Carvalho, 2015, p. 129). Ou seja, é o tempo da produção que adentra as escolas.

Operando ainda com essa perspectiva do ócio e tomando-o como potência para o pensamento, percebemos que ele também é motor para as premissas desse mesmo pensamento, isto é, para aquilo que provoca o pensar, como a contemplação, a escuta atenta, a conversação consigo mesmo, com o outro e com o mundo, uma pausa nas práticas aceleradas e fragmentadas que são as rotinas nas escolas de Educação Infantil. Contudo, para acontecer o ócio, há que não acontecer o "entupimento do tempo" - o tempo da criança totalmente preenchido com as mais variadas aulas, horários e compromissos, em rotinas exaustivas, como um treinamento do ser adulto. Pensando junto e com a escola, questionamos o quanto um currículo entupido abre espaço para a contemplação, para a escuta, para a conversação, para a experiência formativa. Por isso, é importante que nos perguntemos sobre o sentido, o problema e a pergunta (López, 2008).

$\mathrm{Na}$ lógica da pergunta, ressaltamos que, para as práticas educativas 
contemporâneas, de modo geral, o pensar vem sendo relacionado a solucionar problemas, a criar soluções a partir de teorias de base construtivista, o que aparece fortemente nos documentos analisados. Muitas escolas, universidades e campos educacionais valem-se dessa ideia, inclusive, para fazer sua propaganda, partindo do pressuposto de que é disso que a "educação do futuro" precisará. A educação, portanto, vem sendo marcada pelo discurso da solução; aliás, os discursos neoliberais defendem uma educação das habilidades e competências como a solução de vários problemas em um país como o Brasil.

López (2008, p. 62) discorda desse entendimento, afirmando que "a resposta constitui um caso particular de solução de um problema. O problema é a condição da solução, e não o contrário; portanto, o sentido está no problema antes que na solução". Isso quer dizer que o sentido do pensamento está na criação e na elaboração de problemas, e não em suas respostas. Porém, não significa que pensar não possa trazer algumas respostas e soluções, mas que pensar não tem tal fim e não se restringe a isso. O mesmo autor ainda explica: "acredita-se com frequência que os problemas são dados, que existem já prontos e que desaparecem com as respostas ou soluções" (Ibidem, p. 62-63). Todavia, são justamente os problemas que fazem pensar.

A educação, então, ancora-se na formação de sujeitos que sejam capazes de solucionar os problemas na vida rápida contemporânea, com uma também rápida resolução de problemas. Dessa forma, “[...] o pensamento é entendido como a capacidade de encontrar soluções para os problemas, habilidade para neutralizá-los. Assim, pensar equivaleria a procurar soluções" (López, 2008, p. 6). Ainda nesse sentido, cabe ressaltar que, "devido a essa imagem do pensamento, a maioria dos educadores acredita contribuir com o pensamento de seus estudantes quando os convidam a resolver problemas" (Ibidem, p. 63). Entretanto, ao fazerem isso, os educadores enxergam as problemáticas como obstáculos a serem superados, e não como impulso para o pensamento.

O problema não é o outro do saber, é o que dá sentido para perguntas e respostas. A essa ideia, retomamos o que foi constatado na LDB/96, nas DCNEIs/10 e 
pensamento, experiência e o tempo do ócio na educação infantil

na BNCC/18: pensamento operado como competência a ser desenvolvida, pautado no cognitivismo e dividido em partes, séries, estágios, áreas, campos. Com este entendimento, o pensamento é operado como reflexão, fortemente investido pelas práticas avaliativas que buscam registar todos os movimentos das crianças. Essa é uma forte prática discursiva de verdade em se tratando das práticas da Educação Infantil. Comumente, nas escolas, fala-se que "a criança ainda não atingiu determinado estágio de pensamento" quando se quer dizer que ela ainda não está apta para determinado aprendizado. A velha lógica dos pré-requisitos. Este discurso do pensar para resolver problemas e do desenvolvimento de um pensamento 'bom' ou de um 'nível' de pensamento, mostra-se tão forte que gera uma espécie de maratona - da qual fala López (2008) -, entre as instituições nos dias de hoje, produzindo práticas de rankiamento entre alunos e escolas, o que nos faz lembrar a sociedade do desempenho, da qual tanto fala Han (2014), em que acabamos competindo conosco mesmos e pertencendo ainda mais a essa lógica neoliberal.

Assim, poderíamos dizer “que 'pensar' é o ato de colocar problemas, enquanto que 'saber' designa apenas a generalidade do conceito ou a calma posse de uma regra de solução" (López, 2008, p. 63). Entretanto, essa relação com o pensamento pressuporia algumas relações com o tempo que problematizam esta sociedade da aceleração, como a valorização do ócio. Carvalho (2015, p. 124) corrobora o aqui defendido, afirmando que "o tempo das crianças não é o do relógio, mas o da potência dos momentos vivenciados". O tempo do espaço da Escola Infantil não pode ser medido igualmente ao tempo da produtividade, como aqui discutimos.

Assim, “[...] o dar tempo (um tempo à parte da produtividade e da lucratividade) é também, talvez, uma operação fundamental que a escola faz, a primeira condição da educação e o gesto básico do professor" (Larrosa, 2018, p. 23). Faz-se necessário um movimento que parta da escola para promover o tempo do ócio também para o professor, e não somente para as crianças, e "isso significa também liberar o tempo da pressa, da urgência, da preocupação, da necessidade, daquilo que nem se sabe mais o quê. [Liberar o tempo do útil, de] preparação para o ensino 
fundamental [de] preparação para o futuro [de] preparação para ser alguém na vida"

(Ibidem, p. 23). Isso significa procurar brechas em meio aos tempos impostos pelo imediatismo na sociedade em que se vive, em meio às habilidades e competências a serem desenvolvidas. Professores e alunos unidos por uma temporalidade mais atenta ao ócio do que à avaliação e ao registro minucioso de todas as "produções" das crianças.

Alargando essa discussão sobre o tempo, mencionamos algo que, apesar de já muito discutido em diversos trabalhos, é muito importante sob nossa ótica: o sentido de skholé. Masschelein e Simons (2014) auxiliam-nos neste argumento, explicando que, em muitas línguas, a noção de escola (escuela, école, ascuola, skola, Schule, etc.) deriva do grego skholé, que significa, antes de tudo, "tempo livre", mas também: "resto, atraso, estudo, discussão, palestra, prédio da escola. [...], mas vamos considerar, para começar, o sentido de tempo livre" (Ibidem, p. 160). A skholé, para os gregos na Antiguidade Clássica, então, tinha um sentido muito diferente daquele que se tem atualmente sobre uma escola, uma vez que, hoje, ao se pensar em escola, pensa-se em desenvolver habilidades e competências, assim como em muitas instituições pode-se pensar em diversão, lazer, decidir algo 'legal que se quer estudar'. O tempo de ir à skholé era um tempo de "pensamento, estudo e exercício" (Ibidem, p. 160). Um tempo de estudo, exercício e pensamento sobre as coisas do mundo, da vida, sobre aquilo que, de fora do indivíduo, inquietava, incitava, problematizava, causava pensar.

E como pensar que a escola, ainda, pode ser esse lugar potente de ensinar para as crianças diferentes formas de se relacionarem com o tempo, consigo e com os demais?

\section{considerações finais}

Ao trazer os questionamentos sugeridos por López (2015), afirmamos o compromisso da pesquisa e desta escrita dizendo, mais uma vez, que não pretendemos demonizar a escola de Educação Infantil, as políticas públicas educacionais ou/e muito menos tudo aquilo que se faz e se produz em tais espaços. Tampouco acreditamos que 
pensamento, experiência e o tempo do ócio na educação infantil

a aprendizagem e o desenvolvimento não possam ocorrer nessas instituições. Esclarecemos que nosso compromisso é pensar junto e pensar sobre, a fim de problematizar e potencializar o pensamento, sendo o ócio sua condição.

Não defendemos um esvaziamento de repertório cultural e de saberes nas escolas. Pelo contrário, buscamos incitar a pensar sobre a perspectiva das habilidades e competências, sobre a qual alguns documentos, como a Base, foram construídos, sendo fortemente marcados pelos signos da avaliação e do registro. Procuramos pensar na potencialização da Educação Infantil como essa possibilidade de exercício de pensamento e de vida. A escola, segundo Masschelein e Simons (2014) é do "mundo" e para o mundo. Acrescentamos que "a questão não é saber ou aprender quem eu sou, quem você é ou quem somos nós, a questão é cuidar de si como sendo um cuidado que interessa" (Ibidem, p. 165). É a produção de sujeitos não alheios ao mundo onde vivem, não conectados somente às tecnologias nem aos seus interesses individuais ou particulares, mas também conectados com o mundo e com as pessoas. É a produção de sentido de uma existência que esteja além da ordem do discurso.

Podemos problematizar o pensamento retratado nos documentos, reduzido à noção de desenvolvimento, este voltado muito mais para uma recognição do que para uma experiência de si. As DCNEIs/10 e a BNCC/18 apresentaram-se como estratégias pautadas por aquilo que a criança deve aprender. Neste ponto, o argumento central dos documentos contraria parte daquilo que procuramos trazer como questão central: o pensamento.

O exercício do pensamento não é "orientado para" e também não coloca o "conhecimento em primeiro lugar". O exercício do pensamento "diz respeito à questão de como agir e se relacionar com o presente" (Masschelein; Simons, 2014, p. 13). Isso não significa abandono da tradição e de certo repertório cultural. E aí os Campos de Experiência da BNCC ajudam-nos a retomar a importância dessas questões. Todavia, a questão é o quanto podemos problematizar como nos relacionamos com isso, atravessados pelas temporalidades do presente e por certa necessidade de ruminação, para experimentarmos outras relações com nós mesmos, com os demais e com o 
mundo.

Ressaltamos também que, principalmente na BNCC/18, o instrumento como público e como comum a todos destacou-se em meio aos demais "achados". O caráter de tal ofício levou-nos a pensar, juntamente com as leituras de Larrosa (1998), López (2008) e Kohan (2007), que, falando de escola, o pensamento talvez seja o exercício mais comum e público, antes mesmo que o conhecimento. Isso porque "[...] a inabilidade de pensar não é uma imperfeição daqueles muitos a quem falta inteligência, mas uma possibilidade sempre presente para todos" (Arendt, 2000, p. 143). Ou seja, o exercício do pensamento é uma possibilidade comum a todos, é uma possibilidade que convida a "compartilhar" e constituir um "público pensante" que se coloca perante o "não ser ensinado" (Ibidem, p. 17), ao mesmo tempo em que se coloca à prova. E como pensar isso a partir de documentos que, sim, garantem a liberdade de cátedra, a discussão da diversidade do país, das diferentes culturas e modos de vida (questões extremamente importantes e asseguradas em tais documentos), mas que focam no interesse individual e nas competências?

Acreditamos que, enquanto professoras, temos essa necessidade de problematização e, por isso, entendemos que Larrosa (2018, p. 239) nos ajuda a fechar esta conversação quando diz: “[...] são os escolares (os habitantes da escola, os que fazem a escola) que têm que dizer à sociedade (aos políticos e aos economistas) o que é que eles têm que fazer para que a escola continue existindo, ou seja, para que a escola continue sendo escola".

\section{referências}

Agambem, Giorgio. [Sem título]. Belo Horizonte: Gratuita, 2017.

Agostini, Camila Chiodi. As artes de governar o currículo da educação infantil: a base nacional comum curricular em discussão. Orientador Jerzy André Brzozowski. Dissertação de Mestrado em Ciências Humanas. Universidade Federal da Fronteira Sul, Erechim, 2017. Disponível em: https://rd.uffs.edu.br/bitstream/prefix/1566/1/AGOSTINI.pdf. Acesso em: nov 2018.

Arendt, Hannah. Da revolução. Lisboa: Moraes Editores, 1971.

Arendt, Hannah. Entre o passado e o futuro. São Paulo: Perspectiva, 2000.

Barros, Manoel de. Tratado geral das grandezas do infimo. Rio de Janeiro: Record, 2001. 
pensamento, experiência e o tempo do ócio na educação infantil

Bedin Da Costa, Luciano; Bandeira, Larisa da Veiga Vieira; Corrêa, Tatiele Mesquita. Estátuas de nuvens: dicionário de palavras pesquisadas por infâncias. Porto Alegre: Sulina, 2017.

Benjamin, Walter. Reflexões sobre o brinquedo, a criança e a educação. São Paulo: Ed. 34, 2002.

Brasil. Lei no 9.394, de 20 de dezembro de 1996. Institui, no Brasil, as Diretrizes e Bases da Educação Nacional. Brasília/DF: Presidência da República, 1996. Disponível em: http://www.planalto.gov.br/ccivil_03/Leis/L9394.htm. Acesso 20 set. 2017.

Brasil. Ministério da Educação. Secretaria de Educação Básica. Diretrizes Curriculares Nacionais para a Educação Infantil. Brasília/DF: Ministério da Educação, 2010. Disponível em: http://portal.mec.gov.br/dmdocuments/parecer_ceb_22.98.pdf. Acesso 20 de set. 2017.

Brasil. Ministério da Educação. Secretaria de Educação Básica. Base Nacional Comum Curricular. Brasília/DF: Ministério da Educação, 2018. Disponível em: http:/ / basenacionalcomum.mec.gov.br/. Acesso em: abr. 2018.

Carvalho; Rodrigo Saballa de. Entre as culturas da infância e a rotina escolar: em busca do sentido do tempo na educação infantil. Revista Teias, Rio de Janeiro, v. 16, n. 41, p. 124141, abr/jun, 2015.

Carvalho, Rodrigo Saballa de. Fochi, Paulo. "O muro serve para separar os grandes dos pequenos": narrativas para pensar uma pedagogia do cotidiano na educação infantil". Textura, Canoas, v. 18, n. 36, p.153-170, jan./abr. 2016.

Engelman, Selda. Brincar. In: AQUINO, Julio Groppa, Corazza, Sandra Mara (Orgs.). Abecedário: educação da diferença. Campinas, SP: Papirus, 2009.

Foucault, Michel. Estratégia, Poder-Saber. In: Foucault, Michel. Ditos e Escritos V. Rio de Janeiro: Forense Universitária, 2006.

Han, Byung Chul. Sociedade do cansaço. Trad. de Enio Giachini. Petrópolis: Vozes, 2015.

Horn, Cláudia Inês. Documentação pedagógica: a produção da criança protagonista e do professor designer. 2017. Tese de Doutorado em Educação, Universidade do Vale do Rio dos Sinos (UNISINOS), São Leopoldo/RS, 2017. Disponível em: http://www.repositorio.jesuita.org.br/bitstream/handle/UNISINOS/6768/Cl\%E1u dia+In $\%$ EAs

+Horn_.pdf;jsessionid=69A6204E6DA5D3A40CD975E871327B2C?sequence=1. Acesso em: set. 2017.

Kohan, Walter Omar. Infância: Entre a Educação e a Filosofia. Belo Horizonte: Autêntica, 2003.

Kohan, Walter Omar. A infância da educação: o conceito devir-criança. In: KOHAN, Walter Omar (Org.). Lugares da infância: filosofia. São Paulo: DP\&A, 2004. P. 51-71.

Kohan, Walter Omar. O que pode um professor? In: Aquino, Julio Groppa. Rego, Teresa Cristina (Org.). Deleuze pensa a educação. São Paulo: Segmento, 2007. p. 48-57.

Kohan, Walter Omar. Filosofia: O paradoxo de aprender e ensinar. Belo Horizonte: Autêntica, 2009.

Kohan, Walter Omar. Visões de filosofia: infância. Alea, online, v. 17, n. 02, p. 216-226, 2015. Disponível em: http:/ / dx.doi.org/10.1590/1517-106X/172-216.

Kohan, Walter Omar. O mestre inventor: relatos de um viajante. Belo Horizonte: Autêntica: 2017.

Larrosa, Jorge. Pedagogia Profana: Danças, piruetas e mascaradas. Belo Horizonte: Autêntica Editora, 1998.

Larrosa, Jorge. Esperando não se sabe o quê: sobre o ofício do professor. Belo Horizonte: Autêntica, 2018.

López, Maximiliano Valerio. Acontecimento e experiência no trabalho filosófico com crianças. Belo Horizonte: Autêntica Editora, 2008. 
Masschelein, Jan; Simons, Maarten. A pedagogia, a democracia e a escola. Belo Horizonte: Autêntica, 2014.

Pulino, Lúcia Helena Cavasin Zabotto. A brincadeira, o jogo, a criação: crianças e adultos filosofam. In: Kohan, Walter Omar (Org.). Ensino de Filosofia: perspectivas. Belo Horizonte: Autêntica, 2003. P. 213-233.

Ribeiro, Cintya Regina. "Pensamento do fora", conhecimento e pensamento em educação: conversações com Michel Foucault. Educação e Pesquisa, São Paulo, v. 37, n. 3., p. 613628, set/nov. 2011.

Seibert, Deisi Mônica. Uma perspectiva trágica do sofrimento nas práticas escolares. Orientadora Betina Schuler. Dissertação de Mestrado em Educação - Universidade do Vale do Rio dos Sinos (UNISINOS), São Leopoldo, 2019.

Sibilia, Paula. Redes ou paredes: a escola em tempos e dispersão. Trad. de Vera Ribeiro. Rio de Janeiro: Contraponto, 2012.

Silva, Caren. A propósito da infância: errância. In: Rodrigues, Allan; Berle, Simone; Kohan, Walter Omar (Orgs.). Filosofia e educação em errância: inventar a escola, infâncias do pensar. Rio de Janeiro: NEFI, 2018, p.41-57.

recebido em: 16.08 .2020

aprovado em: 17.11 .2020 